OPEN ACCESS

Edited by:

Yibin Feng,

The University of Hong Kong,

Hong Kong

Reviewed by:

Tudor Lucian Pop,

Iuliu Haţieganu University of Medicine

and Pharmacy, Romania

Jianxin Chen,

Beijing University of Chinese

Medicine, China

*Correspondence:

Guo-Qing Zheng

gq_zheng@sohu.com

†These authors have contributed equally to this work

Specialty section

This article was submitted to

Ethnopharmacology,

a section of the journal

Frontiers in Pharmacology

Received: 20 November 2018

Accepted: 04 March 2019

Published: 29 March 2019

Citation:

$X u M-B$, Rong $P-Q$, Jin $T-Y$,

Zhang $P$-P, Liang $H-Y$ and Zheng $G-Q$

(2019) Chinese Herbal Medicine for

Wilson's Disease: A Systematic

Review and Meta-Analysis.

Front. Pharmacol. 10:277.

doi: 10.3389/fphar.2019.00277

\section{Chinese Herbal Medicine for Wilson's Disease: A Systematic Review and Meta-Analysis}

\author{
Meng-Bei Xu ${ }^{\dagger}$, Pei-Qing Rong ${ }^{\dagger}$, Ting-Yu Jin ${ }^{\dagger}$, Pei-Pei Zhang, Hai-Yong Liang and \\ Guo-Qing Zheng *
}

Department of Neurology, The Second Affiliated Hospital and Yuying Children's Hospital of Wenzhou Medical University, Wenzhou, China

Wilson's disease (WD) is a rare autosomal recessive inherited disorder of chronic copper toxicosis. Currently, Chinese herbal medicines (CHM) is widely used for WD. Here, we conducted an updated systematic review to investigate the efficacy and safety of CHM for WD and its possible mechanisms. Randomized-controlled clinical trials (RCTs), which compared CHM with Western conventional medicine or placebo for WD, were searched in six databases from inception to July 2017. The methodological quality was assessed using 7 -item criteria from the Cochrane's collaboration tool. All the data were analyzed using Rev-Man 5.3 software. Eighteen studies involving 1,220 patients were identified for the final analyses. A score of study quality ranged from $2 / 7$ to $4 / 7$ points. Meta-analyses showed that $\mathrm{CHM}$ could significantly increase 24-h urinary copper excretion and improve liver function and the total clinical efficacy rate for WD compared with control ( $p<0.05$ ). Additionally, CHM was well tolerated in patients with WD. The underlying mechanisms of CHM for WD are associated with reversing the ATP7B mutants, exerting anti-oxidation, anti-inflammation, and anti-hepatic fibrosis effects. In conclusion, despite the apparent positive results, the present evidence supports, to a limited extent because of the methodological flaws and CHM heterogeneity, that CHM paratherapy can be used for patients with WD but could not be recommended as monotherapy in WD. Further rigorous RCTs focusing on individual CHM formula for WD are warranted.

Keywords: Wilson's disease, Chinese herbal medicine, ATP7B, anti-oxidation, systematic review

\section{INTRODUCTION}

Wilson's disease (WD) is a rare autosomal recessive inherited disorder that causes copper poisoning in the body, predominantly in the liver and the brain (Walshe, 2009). The global prevalence of WD is between 1 in 5,000 and 1 in 30,000 (Gomes and Dedoussis, 2015). Epidemiological studies have shown a higher incidence and prevalence of WD in China than in western countries $\mathrm{Hu}$ et al., 2011). The WD gene was identified as the trans-membrane copper transporter ATP7B in hepatocytes (Bull et al., 1993; Petrukhin et al., 1993). An absent or reduced function of ATP7B protein causes decreased hepatocellular excretion of copper into bile. In WD, the ever-increasing positive copper balance overwhelms the copper chaperones (copper-binding proteins), causing elevated levels of free copper and copper-induced tissue injury (Patil et al., 2013). Copper metabolism disorder results in multifaceted neurological, hepatic and psychiatric symptoms (Brewer, 2009). When left untreated, WD is fatal. With early diagnosis and appropriate treatment, 
patients can obtain excellent prognosis (Roberts and Schilsky, 2008; Coffey et al., 2013). Currently, medical treatments and liver transplantation are two main therapeutic approaches that can achieve the generation of a negative copper balance (Hedera, 2017). The EASL Clinical Practice Guidelines of Wilson's disease by European Association for Study of Liver recommended D-penicillamine, trientine, zinc, tetrathiomolybdate, and dimercaprol as medications. However, many side effects such as nephrotoxicity, dermatological toxicity, bone marrow toxicity, severe thrombocytopenia, and total aplasia have been observed in patients with lifelong pharmacological therapy (European Association for Study of Liver, 2012). Liver transplantation is an effective treatment for patients of WD with acute liver failure but it is used only in particular scenarios because of the risks including relatively low engrafting efficiency and lifelong immunosuppression (Filippi and Dhawan, 2014). Thus, an alternative and/or complementary strategy for WD is increasingly sought.

Chinese herbal medicine (CHM) is widely used for WD in the clinic (Ren et al., 1997; Han et al., 1999, 2014; Hong et al., 2000; Cui and Zhao, 2001; Xiao, 2003; Xue et al., 2007; Zhang, 2007; Chen and Wang, 2008, 2010; Wang et al., 2010; $\mathrm{Xu}$ et al., 2012a,b; Hu, 2014; Zhang et al., 2014a,b; Fang, 2015; Jiang, 2016; Li et al., 2016), and has been extensively tested by experimental research (Zhang et al., 2011; Lin et al., 2015). Pharmacological studies have shown that CHM can improve the urinary copper excretion and hepatic fibrosis, and protect the brain, liver and kidney (Lutsenko et al., 2007). These beneficial effects are associated with ATP7B gene reversing, anti-oxidant functions, anti-inflammatory actions and suppression of apoptosis (Rosencrantz and Schilsky, 2011). Our group has demonstrated that $\mathrm{CHM}$ brings benefits to some patients with WD (Wang et al., 2012). In addition, emerging randomized-controlled clinical trials (RCTs) continuously report the effectiveness and safety of CHM for WD. Therefore, in the present study we aimed to conduct an updated systematic review of CHM for WD focusing on the clinical evidence and possible mechanisms.

\section{METHODS}

\section{Database and Search Strategies}

Two trained researchers systematically searched the following databases from their inception to July 2017: PubMed, Cochrane Central Register of Controlled Trials, Chinese National Knowledge Infrastructure, Chinese VIP information and WanFang database. The search strategy of PubMed was as follows, and it was modified to suit other English or Chinese databases.

PubMed search strategy:

\#1. Wilson's disease [mh]

\#2. Hepatolenticular degeneration [mh]

\#3. Copper storage disease [tiab]

\#4. Progressive lenticular degeneration [tiab]

\#5. or/1-4

\#6. Medicine, Chinese Traditional [mh]

\#7. Herbal Medicine [mh]
\#8. Integrative Medicine [mh]

\#9. Traditional Chinese medicine [tiab]\#10. herb*[tiab]

\#11. or/6-10

\#12. \#5 and \#11

\#13. Randomized controlled trial [pt]

\#14. Controlled clinical trial [pt]

\#15. Randomized [tiab]

$\# 16$. placebo [tiab]

\#17. drug therapy [sh]

\#18. randomly [tub]

\#19. groups [tub]

\#20. or/13-19

$\# 21$. animals [mph] not (humans [min] and animals [min])

\#22. 20 not 21

\#23. \#12 and \#22

\section{Eligibility Criteria \\ Types of Studies}

Only RCTs were included, irrespective of population characteristics, blinding, publication status, and language. Quasi-RCTs, such as those in which patients were allocated according to date of birth and order of admission number, were excluded.

\section{Types of Participants}

We included participants with a diagnosis of WD, according to Chinese Yang Renmin criteria (1995) (Yang, 1995), Chinese Medical Association of Neurology Guidelines for the diagnosis and treatment of hepatolenticular degeneration (2008) (Chinese Medical Association of Neurology, 2008), American Association for the Study of Liver Diseases practice guidelines of Wilson Disease (2008) (Roberts and Schilsky, 2008), and European Association for the Study of the Liver clinical practice guidelines: Wilson's disease (2012) (European Association for Study of Liver, 2012), regardless of age, gender, disease course and severity. The other diagnostic criteria with comparable definitions were also used.

\section{Types of Interventions}

Analyzed interventions were CHM monotheism or adjunct therapy using any form, any dose or any administrated methods. Comparator treatments were placebo or Western conventional medication (WCM) (Chinese Medical Association of Neurology, 2008; European Association for Study of Liver, 2012). WCM refers to the combination of needed therapies of the following aspects according to the EASL clinical practice guidelines of WD (European Association for Study of Liver, 2012): (1) General supportive care and low copper diet; (2) Medical therapy: D-penicillamine, trientine, zinc, tetrathiomolybdate, or dimercaprol; (3) Liver transplantation. Chinese guideline for diagnoses and treatment of WD (Chinese Medical Association of Neurology, 2008) is similar to the EASL guideline; however, some recommended drugs such as Trientine are not accessible in China, whereby Dimercaprol, including dimercaptosuccinicacid (DMSA) or sodium dimercaptosulphonate (DMPS), are recommended and commonly used for patients with WD. Thus, DMSA or DMPS used as control is also included. 
Studies comparing one kind of CHM therapy to another CHM were excluded.

\section{Types of Outcome Measures}

The primary outcome measures were: (1) the amount of copper excreted in the urine in a $24 \mathrm{~h}$ period, liver function, and the indicator of hepatic fibrosis; (2) clinical deficit score: the Unified Wilson's Disease Rating Scale (Leinweber et al., 2008) or the Novel Global Assessment Scale (GAS) for Wilson's Disease
(Aggarwal et al., 2009); (3) imaging: Brain MRI and functional neuroimaging. The secondary outcome measures were: the total clinical effective rate, laboratory values and adverse events.

\section{Selection and Data Extraction}

The data were extracted using a standardized data extraction form, including study design, eligibility criteria, characteristics of the sample, the course of treatment, interventions, outcomes, the constituent of CHM and pharmaceutical quality control. Reasons

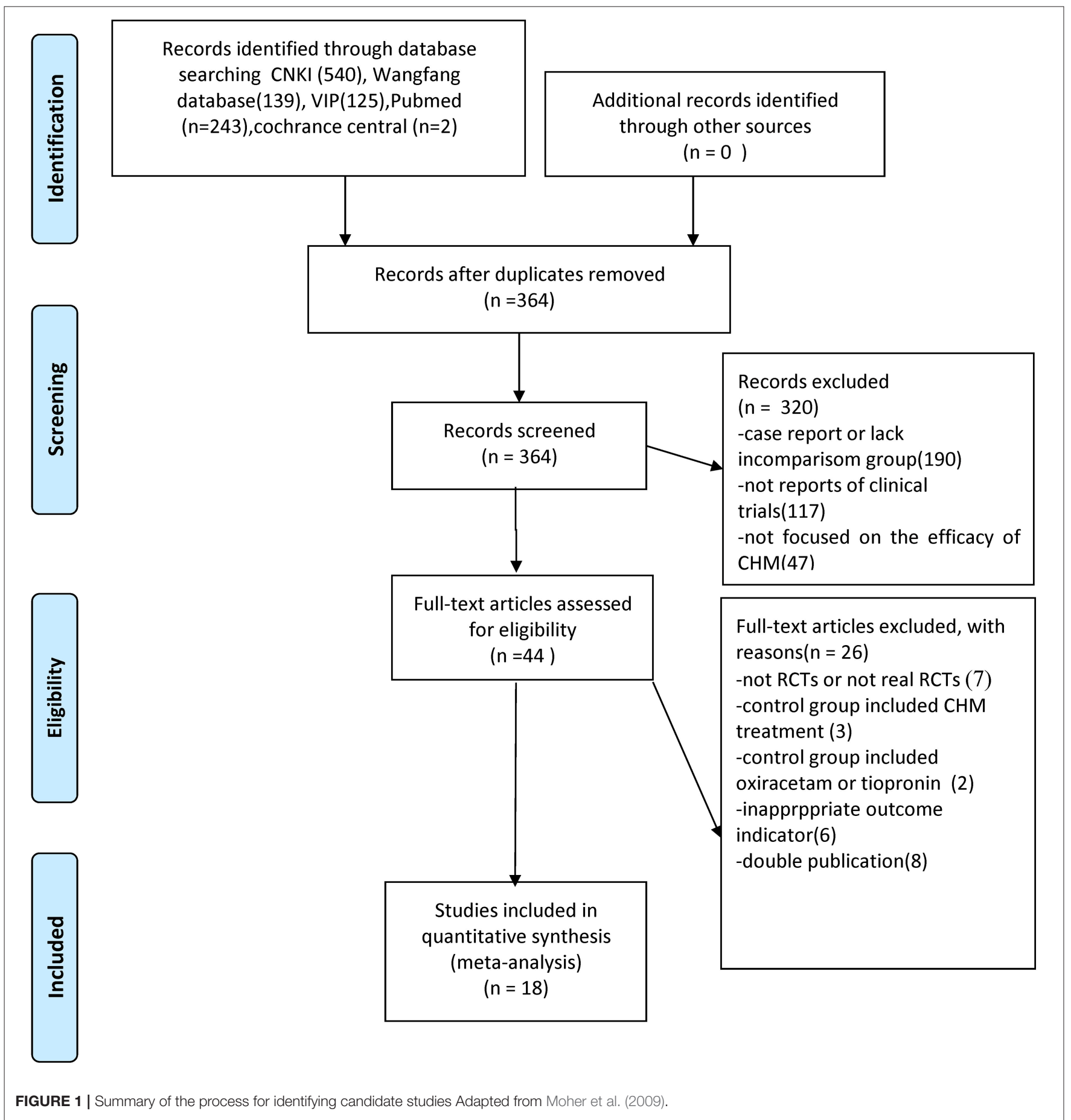


for the exclusion of studies were recorded. Any disagreements were resolved by discussion with or by involving a third author.

\section{Assessment of Risk of Bias}

The RoB of included articles was assessed using the 7-item criteria from the Cochrane's collaboration tool (Higgins et al., 2011). Two authors independently evaluated the study quality, and the final result was identified by discussion when countering the disagreement.

\section{CHM Composition}

The frequency of use of the particular herb was calculated and those used at a high frequency were described in detail.

\section{The Reporting Completeness of the Clinical Studies}

In order to assess the reporting completeness with a rating system quality of the clinical studies, we used a rating system according to our previous articles (Wang et al., 2019) as follows: (1) high quality: full information about the botanical material is provided, including a voucher specimen; (2) moderate quality: only partial information about the botanical material is provided and a voucher specimen is missing; there are taxonomic inaccuracies; (3) low quality: inadequate information and overall taxonomically is inadequate.

\section{Statistical Analysis}

The pooled analyses were carried out with RevMan 5.3 software. Heterogeneity was assessed using the Cochrane Q-statistic test ( $p<0.05$ was considered statistically significant) and the $I^{2}$ statistic test. A fixed effects model $\left(I^{2}<50 \%\right)$ or a random effects model $\left(I^{2}>50 \%\right)$ was used depending on the value of $I^{2}$. Funnel plots were used to visually estimate publication bias. We calculated the standard mean difference (SMD) with 95\% Confidence Intervals (CIs). Sensitivity analyses omitting everyone, which study at a time from the original analysis were conducted to demonstrate our main results to be robust.

\section{RESULTS}

\section{Description of Studies}

We identified 1,049 hints, of which 364 articles remained after removal of duplicates. Through screening titles and abstracts, 320 studies were excluded because they were case reports, they lacked a comparison group, they were not CHM studies or reports of clinical trials. After full-text evaluation of the remaining 44 articles, 26 studies were excluded for the following reasons: (1) 7 articles were not RCTs; (2) 3 articles included CHM treatment in control groups; (3) 2 articles included oxiracetam or tiopronin in control group; (4) 6 articles have inappropriate outcome measures; (5) 8 articles were suspected of being published more than once. Eventually, 18 eligible studies were identified (Figure 1).

\section{Study Characteristics}

Eighteen studies with 1,220 participants were included from 1997 to 2016. The sample size ranged from 33 to 146 with an age of
3 to 59 years. The duration of diseases lasted from 1 month to 31 years. The course of treatment ranged from 28 to 90 days. Five studies (Han et al., 2014; Hu, 2014; Zhang et al., 2014a; Fang, 2015; Jiang, 2016) were diagnosed according to Chinese Medical Association of Neurology (2008), 9 studies (Han et al., 1999; Hong et al., 2000; Xue et al., 2007; Zhang, 2007; Chen and Wang, 2010; Wang et al., 2010; Xu et al., 2012a,b; Zhang et al., 2014b) were diagnosed according to Yang criteria (1995) and 4 studies used comparable definitions (Ren et al., 1997; Cui and Zhao, 2001; Xiao, 2003; Chen and Wang, 2008). Three studies (Han et al., 1999; Chen and Wang, 2008, 2010) used CHM monotherapy, and the others used CHM paratherapy. The control group used penicillamine (Xiao, 2003; Zhang, 2007; Chen and Wang, 2008, 2010), DMSA (Ren et al., 1997; Xiao, 2003; Zhang et al., 2014a; Fang, 2015), DMPS (Hong et al., 2000; Xue et al., 2007; Wang et al., 2010; Xu et al., 2012a,b; Han et al., 2014; $\mathrm{Hu}, 2014$; Zhang et al., 2014b; Jiang, 2016), Zinc sulfate (Cui and Zhao, 2001; Xiao, 2003). The characteristics of the 18 trials are summarized in Table 1. In four studies (Han et al., 1999; Hong et al., 2000; Xiao, 2003; Chen and Wang, 2010), the preparations were made in hospitals including the associated pharmaceutical quality control. Six studies (Wang et al., 2010; Xu et al., 2012b; Han et al., 2014; Zhang et al., 2014a; Fang, 2015; Jiang, 2016) used a commercial preparation and in 8 studies (Ren et al., 1997; Cui and Zhao, 2001; Xue et al., 2007; Zhang, 2007; Chen and Wang, 2008; Xu et al., 2012a; Hu, 2014; Zhang et al., 2014b) no data on quality control were reported. The constituent of CHM and pharmaceutical quality control in each included study was listed in detail in Table 2.

\section{The Reporting Completeness of the Clinical Studies}

We accessed the reporting completeness of the material in each study with a rating system, which is related to the information about the botanical material and voucher specimens. Only two studies (Han et al., 2014; Zhang et al., 2014a) are of high quality, which provided the full information about the botanical material and included voucher specimens. Twelve studies (Ren et al., 1997; Han et al., 1999; Hong et al., 2000; Cui and Zhao, 2001; Xiao, 2003; Xue et al., 2007; Zhang, 2007; Chen and Wang, 2008, 2010; Xu et al., 2012a; Hu, 2014; Zhang et al., 2014b) are of moderate quality, which provided partial information about the botanical material and did not provide voucher specimens. Four studies (Wang et al., 2010; Xu et al., 2012b; Fang, 2015; Jiang, 2016) are of low quality with inadequate information and were overall taxonomically inadequate. The quality of each included clinical study is summarized in Table 3.

\section{Risk of Bias in Included Studies}

The score of RoB ranged from 2/7 to 4/7. Of which, 10 studies got two points (Ren et al., 1997; Cui and Zhao, 2001; Xiao, 2003; Xue et al., 2007; Zhang, 2007; Chen and Wang, 2008, 2010; Xu et al., 2012b; Fang, 2015; Jiang, 2016); 7 studies got three points (Han et al., 1999; Hong et al., 2000; Wang et al., 2010; Xu et al., 2012a; $\mathrm{Hu}, 2014$; Zhang et al., 2014a,b); and 1 study got four points (Han et al., 2014). Two studies (Xu et al., 2012a; Han et al., 2014) described the detailed methods for random sequence generation 


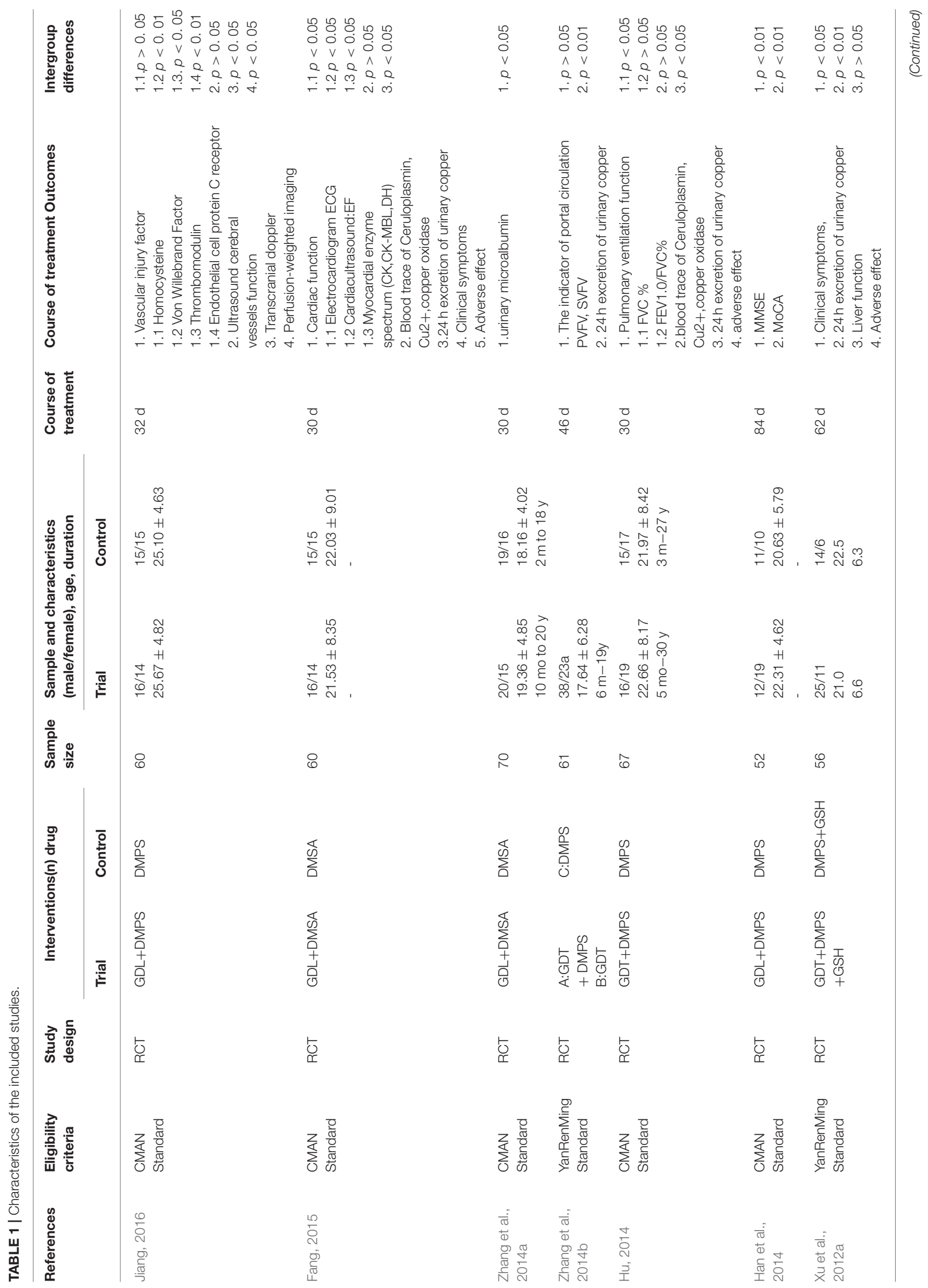



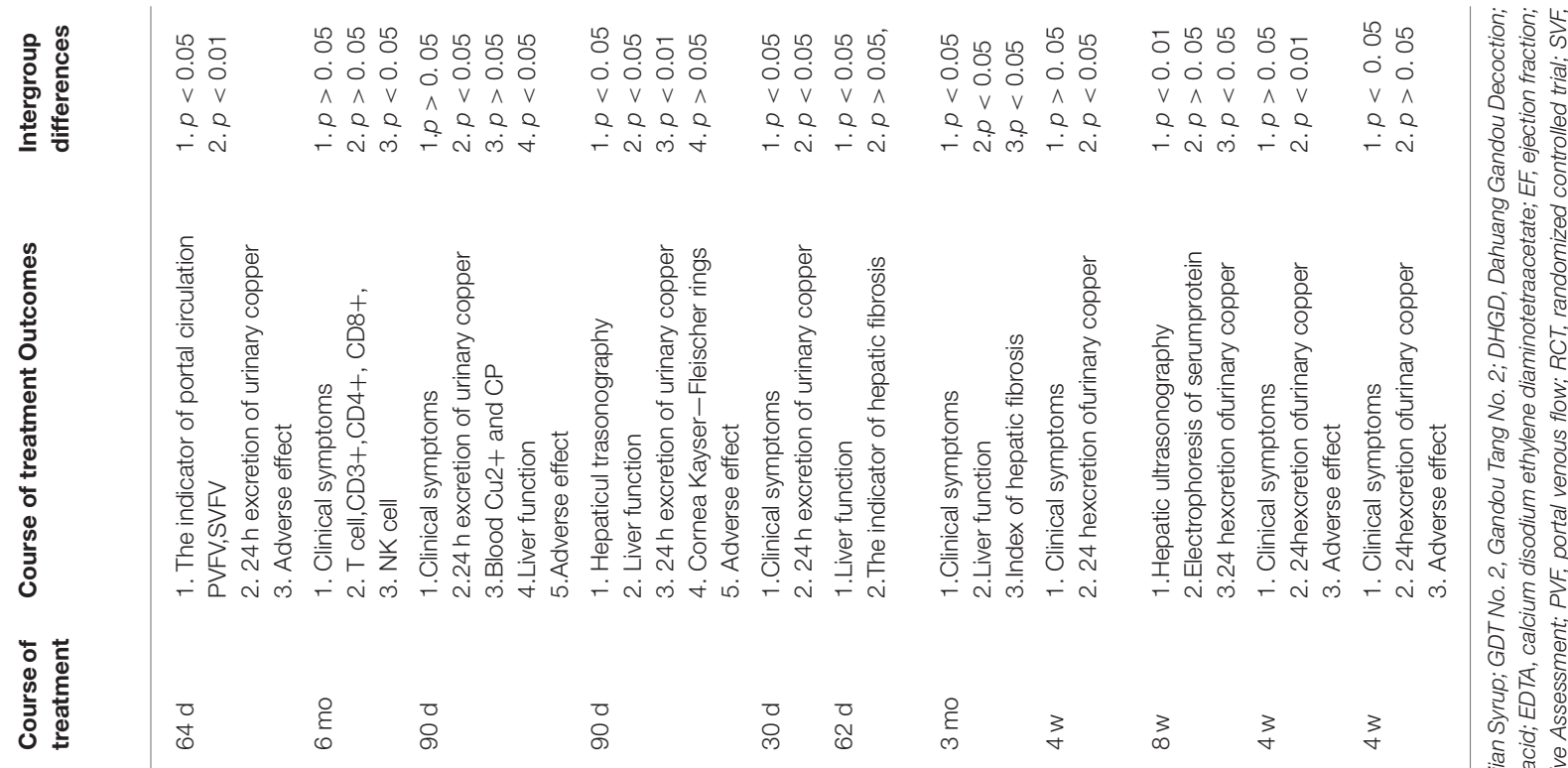

芯出

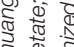

व वे क्षँ वे है 之ं के

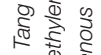
จำ 일 क्ष 0 \% 잉 宁 空藏 को 记

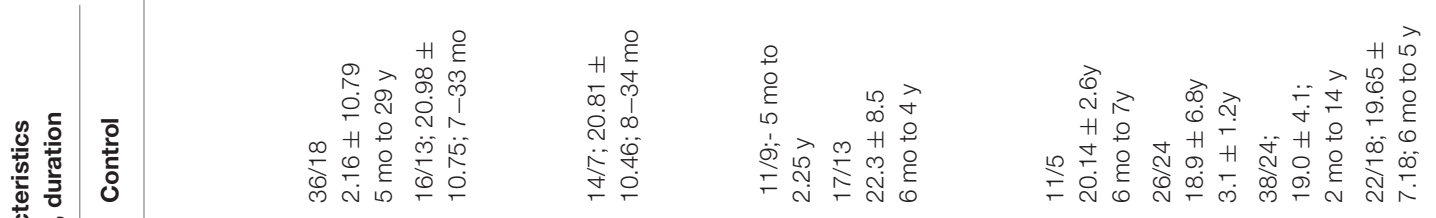

क्ष

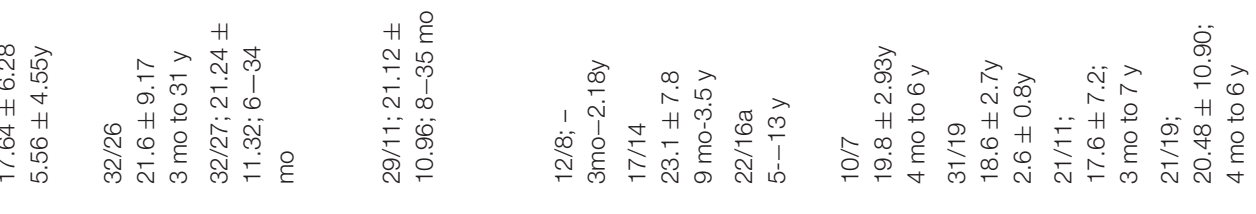

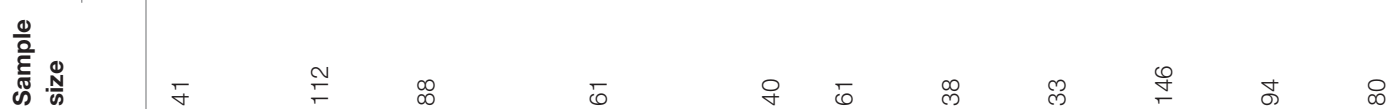

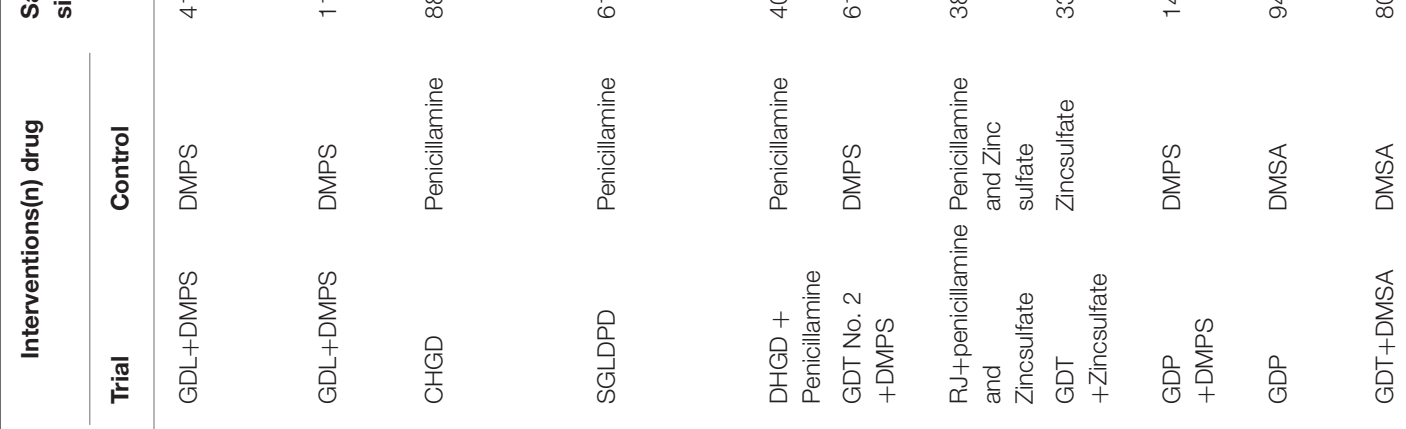

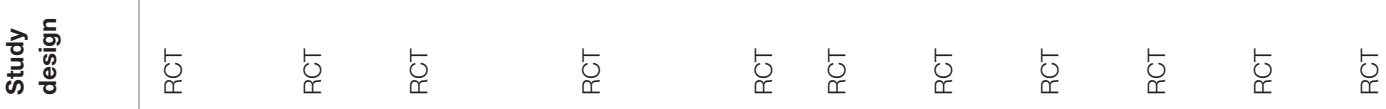

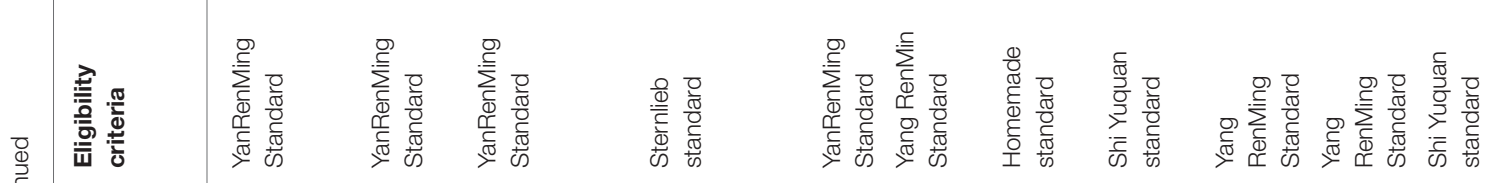


TABLE 2 | Ingredients, usage and quality control of CHM.

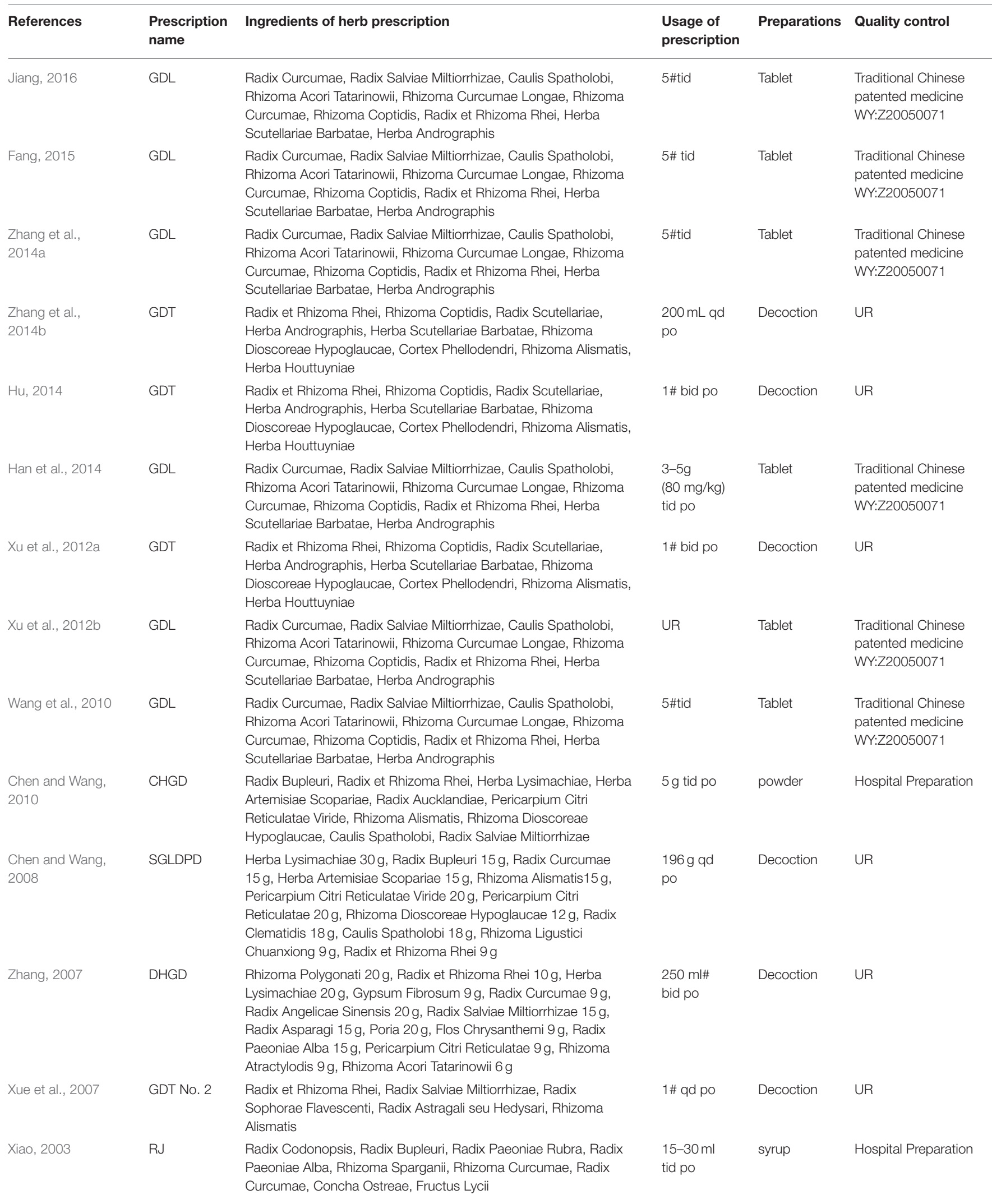


TABLE 2 | Continued

\begin{tabular}{|c|c|c|c|c|c|}
\hline References & $\begin{array}{l}\text { Prescription } \\
\text { name }\end{array}$ & Ingredients of herb prescription & $\begin{array}{l}\text { Usage of } \\
\text { prescription }\end{array}$ & Preparations & Quality control \\
\hline $\begin{array}{l}\text { Cui and Zhao, } \\
2001\end{array}$ & GDT & $\begin{array}{l}\text { Radix et Rhizoma Rhei 6-9 g, Rhizoma Coptidis } 20 \mathrm{~g} \text {, Radix } \\
\text { Scutellariae } 20 \mathrm{~g} \text {, Herba Scutellariae Barbatae } 20 \mathrm{~g} \text {, Herba } \\
\text { Andrographis } 20 \mathrm{~g} \text {, Rhizoma Dioscoreae Hypoglaucae } 20 \mathrm{~g}\end{array}$ & $\begin{array}{l}250 \mathrm{ml} \text { bid } \\
\text { po }\end{array}$ & Decoction & UR \\
\hline Hong et al., 2000 & GDP & $\begin{array}{l}\text { Radix et Rhizoma Rhei } 0.25 \mathrm{~g} \text {, Rhizoma Coptidis } 0.25 \mathrm{~g} \text {, Rhizoma } \\
\text { Curcumae Longae } 0.25 \mathrm{~g} \text {, Herba Lysimachiae } 0.625 \mathrm{~g} \text {, Rhizoma } \\
\text { Alismatis } 0.625 \mathrm{~g} \text {, Radix Notoginseng } 0.042 \mathrm{~g}\end{array}$ & $\begin{array}{l}<15 \text { years } \\
\text { old: } 6 \# \text { tid } \\
\text { po } \\
\geq 15 \text { years } \\
\text { old: } 8 \# \\
\text { tid po }\end{array}$ & Tablet & $\begin{array}{l}\text { Hefei Chinese Medicine } \\
\text { Factory }\end{array}$ \\
\hline Han et al., 1999 & GDP & $\begin{array}{l}\text { Radix et Rhizoma Rhei } 0.25 \mathrm{~g} \text {, Rhizoma Coptidis } 0.25 \mathrm{~g} \text {, Rhizoma } \\
\text { Curcumae Longae } 0.25 \mathrm{~g} \text {, Herba Lysimachiae } 0.625 \mathrm{~g} \text {, Rhizoma } \\
\text { Alismatis } 0.625 \mathrm{~g} \text {, Radix Notoginseng } 0.042 \mathrm{~g}\end{array}$ & $\begin{array}{l}<15 \text { years } \\
\text { old: } 6 \# \text { tid } \\
\text { po } \\
\geq 15 \text { years } \\
\text { old: } 8 \# \\
\text { tid po }\end{array}$ & Tablet & $\begin{array}{l}\text { Hefei Chinese Medicine } \\
\text { Factory }\end{array}$ \\
\hline
\end{tabular}

GDL, Gandouling Tablet; SGLDPD, Shugan Lidan Paidu Decoction; CHGD, Chaihuang Gandou Powder; GDT, Gandou Tang; GDP, Gandou Pian; RJ, Ruaniian Syrup; GDT No. 2, Gandou Tang No. 2; DHGD, Dahuang Gandou Decoction; UR, Unreported.bid, bis in die; d:day; po, peros; qd, quaquedie; tid, ter in die;\#, tablet.

and no studies described allocation concealment. No blinding on patients or personnel was applied. All studies reported dropout data. Ten studies (Cui and Zhao, 2001; Xiao, 2003; Xue et al., 2007; Zhang, 2007; Chen and Wang, 2008, 2010; Xu et al., 2012a,b; Fang, 2015; Jiang, 2016) were judged as unclear risk of bias for selective reporting. There were baseline comparisons and patients' consent were well reported, and other biases were not found in all included studies. The RoB in each included study is concluded in Table 4.

\section{Effectiveness}

\section{CHM vs. Placebo}

None of RCTs used a specific comparison between CHM and placebo.

\section{CHM vs. WCM}

Two studies (Chen and Wang, 2008, 2010) showed that CHM monotherapy had no significance for increasing the amount of copper excreted in the urine in a $24 \mathrm{~h}$ period $(n=149$, SMD $-1.32,95 \%$ CI $[-1.70$ to -0.95$], p<0.01$; heterogeneity: $\left.\chi^{2}=0.02, \mathrm{df}=1(p=0.88) ; I^{2}=0 \%\right)$ (Figure 2).

\section{CHM Plus WCM vs. WCM}

\section{4 hexcretion of urinary copper}

Nine studies were included. Meta-analysis of 5 studies (Xu et al., 2012a,b; Hu, 2014; Zhang et al., 2014b; Fang, 2015) reported a significant effect of CHM on increasing the amount of $24 \mathrm{~h}$ excretion of urinary copper in patients with WD compared to the control $(n=228$, SMD 0.93, 95\% CI [0.65 to 1.21$], p<0.01$; heterogeneity: $\chi^{2}=$ 4.01, $\left.\mathrm{df}=4(p=0.40) ; I^{2}=0 \%\right)$ (Figure 3). Four studies (Ren et al., 1997; Hong et al., 2000; Cui and Zhao, 2001; Zhang, 2007) failed for pool analysis because the measurement unit of $24 \mathrm{~h}$ excretion of urinary copper was different from the remaining. However, they all got the significant effects of improving the $24 \mathrm{~h}$ excretion of urinary copper on patients $(p<0.05)$.

\section{Liver function and the indicator of hepatic fibrosis}

Two studies (Xue et al., 2007; Xu et al., 2012a) used the value of serum alanine aminotransferase (ALT) as the indicator of liver function. Pooled data showed that CHM was significantly better at decreasing the ALT compared with control group $[n=117$, SMD $-0.62,95 \%$ CI $[-1.00$ to -0.24$], p<0.01$; heterogeneity: $\left.\chi^{2}=1.40, \mathrm{df}=1(p=0.24) ; I^{2}=29 \%\right]$, (Figure 4). One study (Xiao, 2003) used ALT recovery rate as the indicator of liver function, and it demonstrated significant effects on decreasing the ALT $(p<0.05)$. One study (Xiao, 2003) showed that CHM had significant effects on reducing HA, PCIII, and LN ( $p<0.05$ ), however, another study (Xue et al., 2007) showed that CHM had no effect on reducing HA, PCIII and LN in short time $(p>0.05)$.

\section{The total clinical effective rate}

Data on the rate of total clinical effectiveness were available from eight studies with 487 participants included. Meta-analysis of 8 studies showed a significant effect of CHM on increasing the total clinical effective rate compared with control group $(n=487, \mathrm{RR}$ 1.27, $95 \%$ CI [1.15 to 1.39 ], $p<0.01$; heterogeneity: $\chi^{2}=6.56$, $\left.\mathrm{df}=7(p=0.48), I^{2}=0 \%\right)($ Figure 5).

\section{Laboratory values or imaging indices}

One study (Xu et al., 2012b) showed that CHM paratherapy is significant for increasing portal venous flow (PVF) and splenic vein flow (SVF) $(p<0.05)$ compared with WCM, whereas another study (Zhang et al., 2014b) showed no difference. One 
TABLE 3 | The quality of the clinical studies.

\begin{tabular}{|c|c|c|c|}
\hline References & $\begin{array}{l}\text { Botanical material } \\
\text { information }\end{array}$ & $\begin{array}{l}\text { Voucher } \\
\text { specimen }\end{array}$ & Quality \\
\hline Zhang et al., 2014a & $\mathrm{P}$ & + & High \\
\hline Han et al., 2014 & $\mathrm{P}$ & + & High \\
\hline Zhang et al., 2014b & $\mathrm{P}$ & - & Moderate \\
\hline $\mathrm{Hu}, 2014$ & $\mathrm{P}$ & - & Moderate \\
\hline Xu et al., $2012 a$ & $P$ & - & Moderate \\
\hline Chen and Wang, 2010 & $\mathrm{P}$ & - & Moderate \\
\hline Chen and Wang, 2008 & $\mathrm{P}$ & - & Moderate \\
\hline Zhang, 2007 & $\mathrm{P}$ & - & Moderate \\
\hline Xue et al., 2007 & $P$ & - & Moderate \\
\hline Xiao, 2003 & $P$ & - & Moderate \\
\hline Cui and Zhao, 2001 & $\mathrm{P}$ & - & Moderate \\
\hline Hong et al., 2000 & $\mathrm{P}$ & - & Moderate \\
\hline Han et al., 1999 & $\mathrm{P}$ & - & Moderate \\
\hline Ren et al., 1997 & $\mathrm{P}$ & - & Moderate \\
\hline Jiang, 2016 & 1 & + & Low \\
\hline Fang, 2015 & 1 & + & Low \\
\hline Xu et al., 2012b & 1 & + & Low \\
\hline Wang et al., 2010 & I & + & Low \\
\hline
\end{tabular}

F. Full information about the botanical material is provided; $P$, Partial information about the botanical material is provided; I, Inadequate information about the botanical material is provided; +, includes a voucher specimen; -, a voucher specimen is missing.
TABLE 4 | Risk of bias of the included studies.

\begin{tabular}{lcccccccc}
\hline Included studies & A & B & C & D & E & F & G & Total \\
\hline Jiang, 2016 & $?$ & 0 & 0 & 0 & 1 & $?$ & 1 & 2 \\
Filippi and Dhawan, 2014 & $?$ & 0 & 0 & 0 & 1 & $?$ & 1 & 2 \\
Zhang et al., 2014a & $?$ & 0 & 0 & 0 & 1 & 1 & 1 & 3 \\
Zhang et al., 2014b & $?$ & 0 & 0 & 0 & 1 & 1 & 1 & 3 \\
Hu, 2014 & $?$ & 0 & 0 & 0 & 1 & 1 & 1 & 3 \\
Han et al., 2014 & 1 & 0 & 0 & 0 & 1 & 1 & 1 & 4 \\
Xu et al., 2012a & 1 & 0 & 0 & 0 & 1 & $?$ & 1 & 3 \\
Xu et al., 2012b & $?$ & 0 & 0 & 0 & 1 & $?$ & 1 & 2 \\
Wang et al., 2010 & $?$ & 0 & 0 & 0 & 1 & 1 & 1 & 3 \\
Chen and Wang, 2010 & $?$ & 0 & 0 & 0 & 1 & $?$ & 1 & 2 \\
Chen and Wang, 2008 & $?$ & 0 & 0 & 0 & 1 & $?$ & 1 & 2 \\
Zhang, 2007 & $?$ & 0 & 0 & 0 & 1 & $?$ & 1 & 2 \\
Xue et al., 2007 & $?$ & 0 & 0 & 0 & 1 & $?$ & 1 & 2 \\
Xiao, 2003 & $?$ & 0 & 0 & 0 & 1 & $?$ & 1 & 2 \\
Cui and Zhao, 2001 & $?$ & 0 & 0 & 0 & 1 & $?$ & 1 & 2 \\
Hong et al., 2000 & $?$ & 0 & 0 & 0 & 1 & 1 & 1 & 3 \\
Han et al., 1999 & $?$ & 0 & 0 & 0 & 1 & 1 & 1 & 3 \\
Ren et al., 1997 & $?$ & 0 & 0 & 0 & 1 & 1 & 1 & 2 \\
\hline Coch & & & & & & &
\end{tabular}

Cochrane Collaboration's tool: A, Random sequence generation; B, Allocation concealment; C, Blinding of participants or personnel; D, Blinding of outcome assessment; E, Incomplete outcome data; F, Selective reporting; G, Anything else; 1, Low risk of bias; 0 , High risk of bias; ?, Uncertain risk of bias.

The full and validated botanical names of herbs were generalized in Table 5.

\section{The Possible Mechanisms of CHM for WD}

The possible mechanisms of the most frequently used herbs and the main active ingredients are as follows: (1) Curcumin: an active ingredient from commonly used herbs like Rhizoma Curcumae Longae, Rhizoma Curcumae, Radix Curcumae and Radix Curcumae can partially restore protein expression of most ATP7B mutants to restore functional copper export (van den Berghe et al., 2000; Zhang et al., 2011; European Association for Study of Liver, 2012). Furthermore, curcumin is an ideal antioxidant, an effective scavenger of reactive oxygen species (Samarghandian et al., 2017), and it exerts anti-fibrotic effect through regulating hepatic stellate cells (HSCs) function (Jin et al., 2016; Liu et al., 2016; Mustafa, 2016). (2) Radix et Rhizoma Rhei: Rhubarb root and its active components have anti-oxidation (Shia et al., 2009), anti-fibrotic (Jin et al., 2005), and antiinflammation effects (Hwang et al., 2013). (3) Rhizoma Coptidis: Berberine from Rhizoma Coptidis exerted anti-fibrotic and antioxidation effects (Zhang et al., 2008). (4) Herba Scutellariae Barbatae: P-coumaric acid from Herba Scutellariae Barbatae possess anti-oxidative activities (Ibrahim et al., 2007) and reverse the ATP7B function defect via regulating pre-mRNA splicing (Lin et al., 2015). (5) Herba Andrographis: Andrographolide from Herba Andrographis displayed anti-inflammatory activity through reducing the expression of pro-inflammatory mediators (Panossian et al., 2002) and exhibited hepatoprotective effects through anti-oxidative effect (Vetriselvan et al., 2011). 


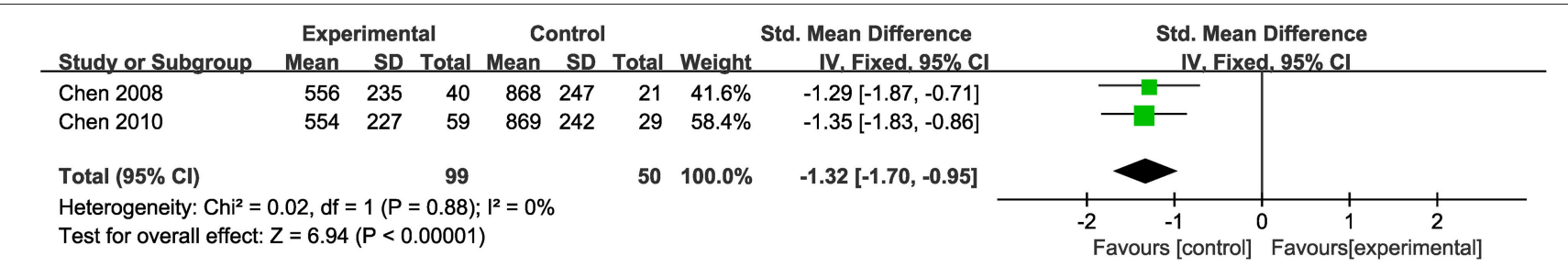

FIGURE 2 | The forest plot: The $24 \mathrm{~h}$ excretion of urinary copper of CHM vs. WCM.

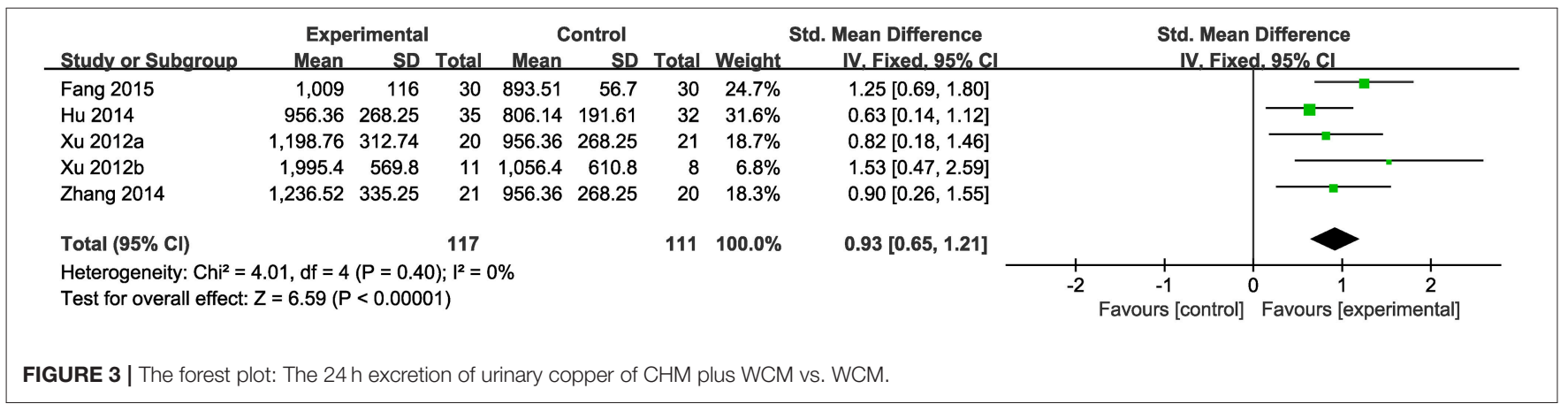

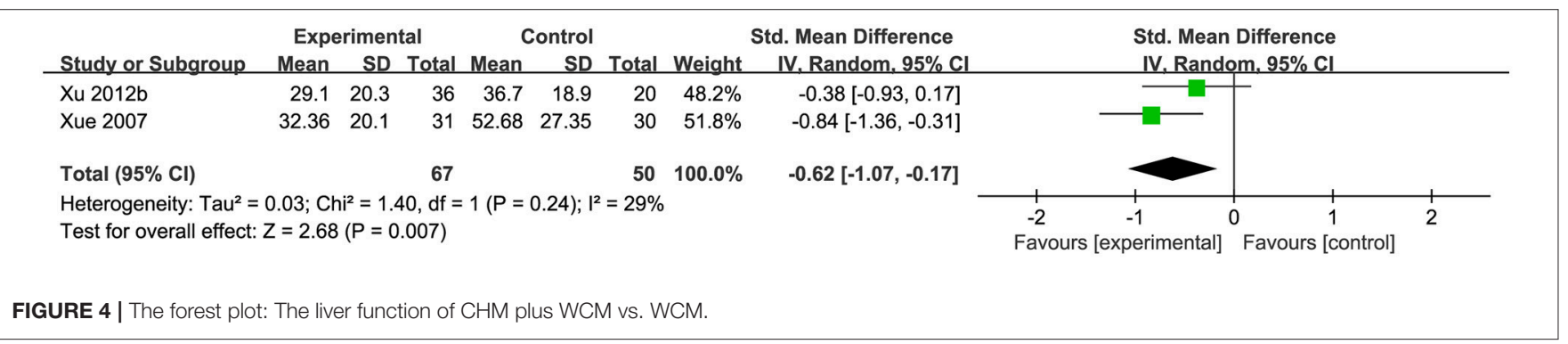

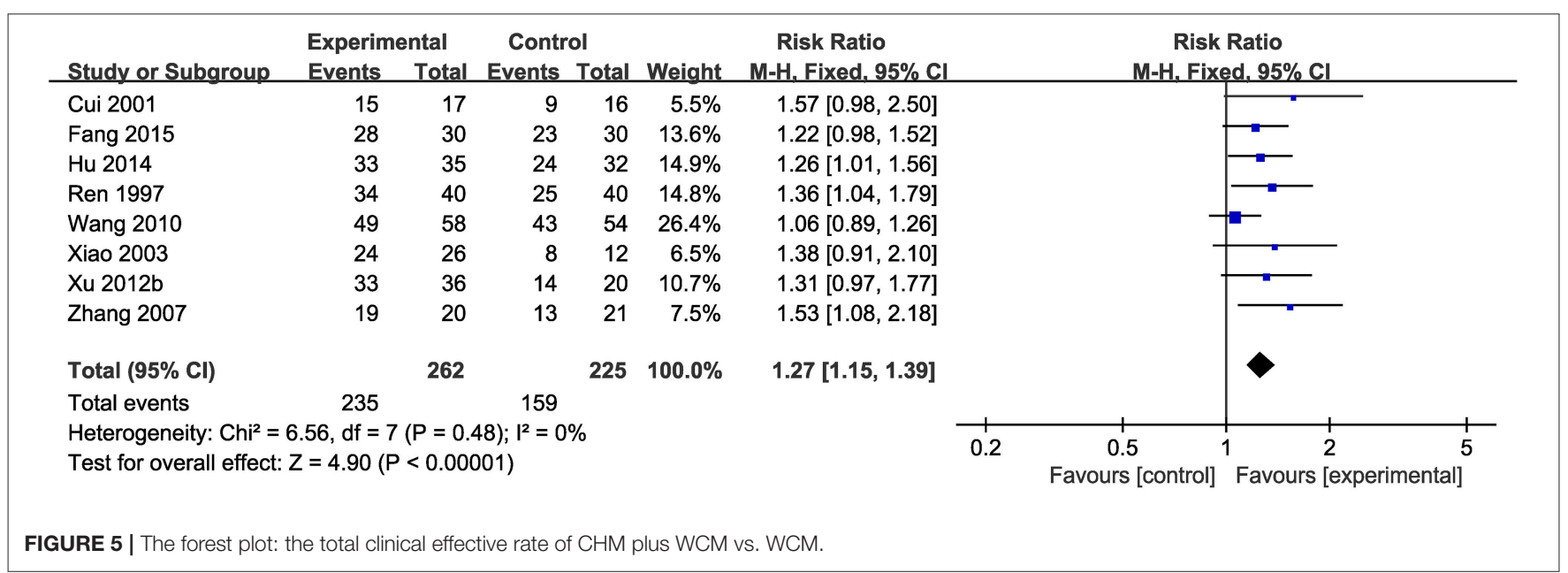

\section{DISCUSSION}

\section{Summary of Evidence}

Eighteen RCTs involving 1,220 patients suffering from WD were identified. The main findings of this study were that $\mathrm{CHM}$ adjuvant therapy could increase $24 \mathrm{~h}$ urinary copper excretion, and improve liver function and the total clinical efficacy rate for WD. Two trails (Chen and Wang, 2008, 2010) indicated that CHM monotherapy was not superior to the WCM. Eight out of eighteen studies reported no serious adverse events relevant to 
TABLE 5 | Details of the most commonly used herbs for WD.

\begin{tabular}{|c|c|c|c|c|c|}
\hline Chinese name & Pharmaceutical name & Species & Family & Record & $\mathrm{N} / 18(\%)$ \\
\hline Dahuang & Radix et Rhizoma Rhei & Rheum officinale Baill. & Polygonaceae & - & $17(94 \%)$ \\
\hline Huanglian & Rhizoma Coptidis & Coptis chinensis Franch. & Ranunculaceae & - & $13(72 \%)$ \\
\hline Banzhilian & Herba Scutellariae Barbatae & Scutellaria barbata D.Don & Lamiaceae & 188943 & $11(61 \%)$ \\
\hline Chuanxinlian & Herba Andrographis & Andrographis paniculata (Burm.f.) Nees & Acanthaceae & - & $11(61 \%)$ \\
\hline Danshen & Radix Salviae Miltiorrhizae & Salvia miltiorrhiza Bunge & Lamiaceae & 183206 & $9(50 \%)$ \\
\hline Zexie & Rhizoma Alismatis & Alisma orientale (Sam.) Juz. & Alismataceae & 294832 & $9(50 \%)$ \\
\hline Ezhu & Rhizoma Curcumae & Curcuma phaeocaulis Valeton & Zingiberaceae & 235270 & $9(50 \%)$ \\
\hline Yujin & Radix Curcumae & Curcuma wenyujin Y.H.Chen \& C.Ling & Zingiberaceae & 235308 & $9(50 \%)$ \\
\hline Jianghuang & Rhizoma Curcumae Longae & Curcuma longa L. & Zingiberaceae & 235249 & $8(44 \%)$ \\
\hline Shichangpu & Rhizoma Acori Tatarinowii & Acorus tatarinowii Schott & Acoraceae & 2337 & $7(39 \%)$ \\
\hline Jixueteng & Caulis Spatholobi & Spatholobus suberectus Dunn & Leguminosae & 32974 & $8(44 \%)$ \\
\hline Huangqin & Radix Scutellariae & Scutellaria baicalensis Georgi & Lamiaceae & 188938 & $5(28 \%)$ \\
\hline Jinqiancao & Herba Lysimachiae & Lysimachia christinae Hance & Primulaceae & - & $5(28 \%)$ \\
\hline
\end{tabular}

CHM formulas, indicating that CHM formulas were generally safe and well tolerated for patients with WD. The possible mechanisms are associated with reversing the ATP7B mutants, and exerting anti-oxidation, anti-inflammation and anti-fibrotic effects. Thus, the findings of the present study suggested, to a limited extent, that CHM paratherapy can be used for WD according to the methodological flaws, whereas the beneficial use of CHM monotherapy for WD still lacks evidence.

\section{Limitations}

There are several limitations in the primary studies. Firstly, although we included RCTs, some inherent and methodological weaknesses still existed in the primary studies: only 2 trials provided sufficient information on how the random allocation was generated, while none of the other trials included reported the allocation concealment. No study employed the blinding procedure, making it difficult to bias results intentionally or unintentionally and to help ensure the credibility of study conclusions. A placebo effect is conceptually defined as the beneficial effect associated with an intervention that does not include the presumed active ingredients; however, CHM placebo are hard to mimic identical interventional herbal prescription due to the fact that CHM is special in color, smell and taste. Thus, placebo-controlled randomized trials are well-recognized method when evaluating the efficacy of $\mathrm{CHM}$ treatment. In addition, most trials are without calculating the formal pretrial sample size. The trials with inadequate sample sizes seem to be one risk in exaggerating intervention benefits. Secondly, WD is a chronic disease, which needs life-long treatments. Long-term efficacy and safety are important assessments to determine the clinical effectiveness of an agent in treatment. However, in the present study, treatment duration ranged from 28 to 90 days. Long-term safety of CHM for WD could not be determined because duration of treatment is short and dropouts were only reported in one study. According to other clinical trials for WD (Brewer et al., 2009; Weiss et al., 2015; Nicholl et al., 2017), it is recommended that the treatment duration of further trials must not be $>60$ days, and must last more than 1 year. Thirdly, clinical heterogeneity would be very significant due to the variations in study quality, intervention of CHM prescriptions, comparators, and outcome measures. Owing to being highly variable in composition and dosage of CHMs, it is difficult to assess the efficacy of a specific CHM by performing pooling analysis. Fourthly, all trials were conducted in China, which may limit the generalizability. Further international multicenter RCTs of CHM for WD are needed, in order to generalize the results worldwide.

\section{Implications for Practice}

Use of CHM for WD patients has increased in the past decades. However, the choice of CHM is mainly empirical and lacking consensus among clinical doctors. The available evidence from the present study supported, to a limited extent, that $\mathrm{CHM}$ paratherapy can be used for patients with WD but should not be recommended as monotherapy in WD. In addition, the most frequently used herbs selected by the present study should be considered as herbal prescription for WD and as a candidate for further clinical trials.

\section{Implications for Research}

In the present study, we identified an area that is worthy of further study. Firstly, the potential benefit of CHM as an adjunct treatment for WD still needs to be further confirmed by high-quality RCTs. Thus, we recommend that CONSORT 2010 statement (Schulz et al., 2010), CONSORT for CHM Formulas (Cheng et al., 2017), and RCTs investigating CHM (Flower et al., 2011) should be used as the guidelines when the designing, registering and reporting of further RCTs. Secondly, WD was thought of as a "rare" autosomal disorder by neurologists, and it proved difficult to conduct large sample RCT. However, this review identified 1,220 subjects with WD from 1997 to 2016. If the primary clinical data of all RCTs were recorded in standard, the evidence would be more reliable. Thus, it is necessary to promote clinical data sharing, as has been suggested by the International Committee of Medical Journal Editors (ICMJE) (Taichman et al., 2017).

WD is caused by ATP7B mutations, resulting in copper accumulation and toxicity. The possible mechanisms of CHM for 
WD not only involve the targets of the ATP7B gene, but also the multiple targets of copper accumulation in various tissues and organs. Curcumin and P-coumaric acid were reported to reverse the ATP7B function defect. Curcumin could partially restore protein expression by directly enhancing the protein expression of mutant ATP7B with residual copper export activity (van den Berghe et al., 2000; Zhang et al., 2011; European Association for Study of Liver, 2012). The EASL Guidelines recommended that treatment with curcumin might be a novel therapeutic strategy in WD (European Association for Study of Liver, 2012). Pcoumaric acid, another ingredient of herbs, can also reverse the ATP7B function defect via a different mechanism by regulating pre-mRNA splicing (Lin et al., 2015).

Copper accumulates in hepatocytes where it induces damage through oxidative stress due to its highly reactive redox capacity (Rosencrantz and Schilsky, 2011). In addition, necrosis and apoptosis triggered immune reaction and inflammation to activate the quiescent HSCs, causing hepatic fibrosis (Jin et al., 2016). The possible pharmacological mechanisms of CHM for copper accumulations of WD are as follows: (1) Antioxidant effects: Curcumin, Anthraquinone (from Radix et Rhizoma Rhei), Danshensu and Salvianolic acid B (from Radix Salviae Miltiorrhizae), were shown to ameliorate the oxidative stress by reducing oxidative stress parameters malondialdehyde, thereby improving the hepatic glutathione content and hepatic superoxide dismutase (SOD) (Liu et al., 2016; Samarghandian et al., 2017), inhibiting the formation of superoxide anions (Shia et al., 2009), and exerting a low level of lipid peroxidase (Mishra et al., 2014; Lee et al., 2016, 2017), leading to maintenance of mitochondrial activity (Zhou et al., 2015). Radix
Scutellariae improved the antioxidant capacity by induction of the antioxidative enzymes and removal of reactive oxygen species (ROS) (Pan et al., 2015). P-coumaric acid (Ibrahim et al., 2007), Andrographolideand (Vetriselvan et al., 2011), Caulis Spatholobi (Jeon et al., 2008) and Tanshinone IIA, (Shu et al., 2016) have also been shown to exhibit antioxidant effects; (2) Anti-inflammatory effects: Emodin (from Radix et Rhizoma Rhei), Andrographolide (from Herba Andrographis), Radix Salviae Miltiorrhizae and Curcumin analog demonstrated anti-inflammatory properties by reducing the expression of proinflammatory mediators via the NF-kB activation pathway (Lee et al., 2003; Hwang et al., 2013; Yue et al., 2014) and MAPK/AP-1 pathway (Choi et al., 2013), and by inhibiting iNOS and COX-2 expression (Paulino et al., 2016). The bioactive components from Radix Scutellariae (Liu et al., 2016) and Quercetin from Herba Lysimachiae (Wang et al., 2015) have been reported to exhibit anti-inflammatory activity; (3) Anti-fibrotic effects: activation of quiescent HSCs is the major event in hepatic fibrosis (Jin et al., 2016). Skullcapflavone I (from Radix Scutellariae) (Park et al., 2005) and Curcumin (Jin et al., 2016) exerted antifibrotic effects by inducing apoptosis or senescence in activated HSCs. Furthermore, Curcumin was found to be an anti-fibrotic mediator that inhibits HSCs activation and the transition to myofibroblast-like cells (Mustafa, 2016). In contrast, Radix et Rhizoma Rhei exerted anti-fibrotic effects by the direct inhibition of stellate cell activation without reducing hepatocyte cell death (Jin et al., 2005). Salvianolic acid A and B from Danshen (Tsai et al., 2011), Berberine (Zhang et al., 2008), Radix Scutellariae (Chen et al., 2013) and Radix et Rhizoma Rhei (Pan et al., 2015) have been reported to prevent hepatic fibrosis in different aspects,

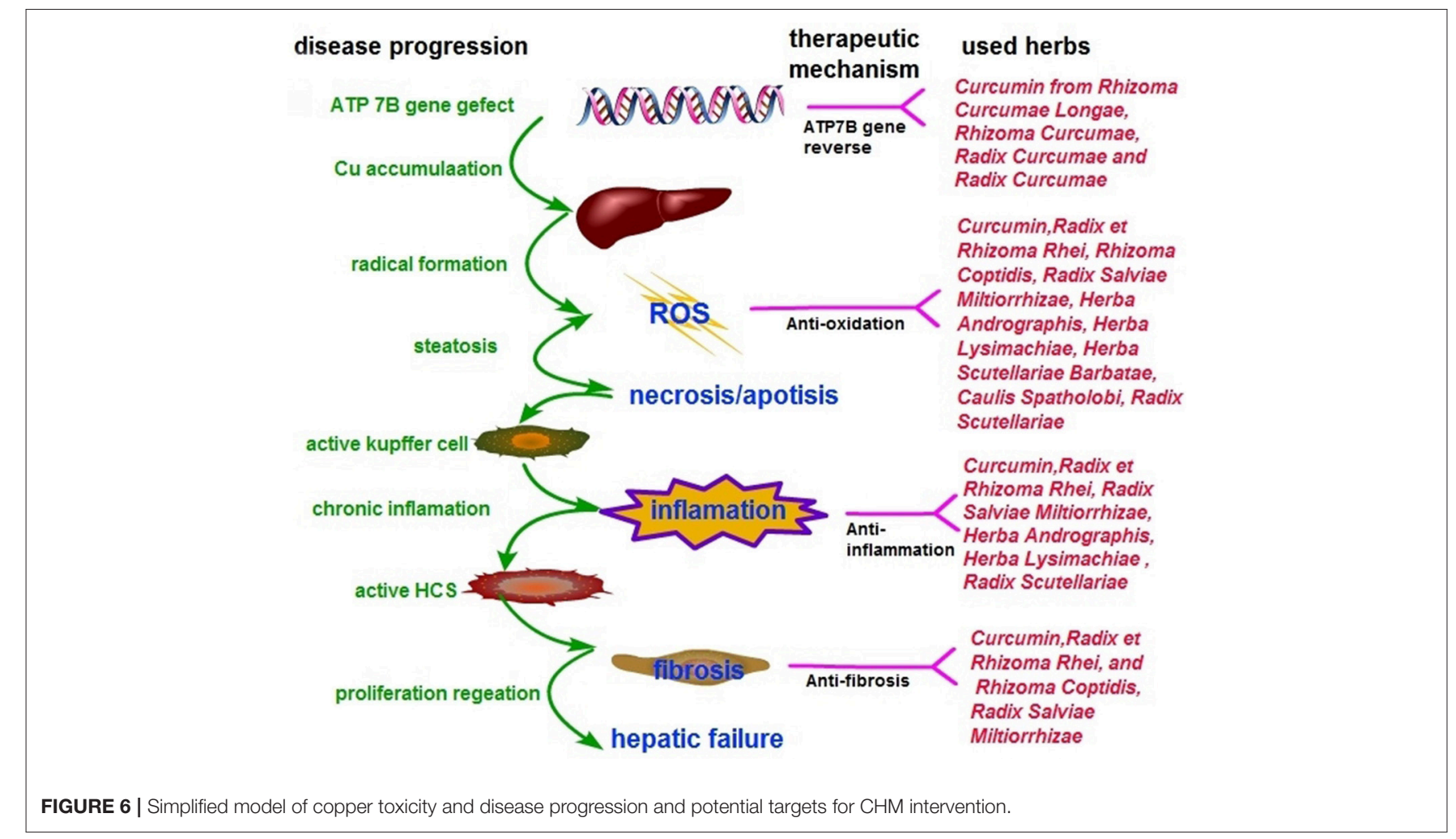


including inhibition of proliferation and fibrogenesis of HSCs, and regulation of the antioxidant system and lipid peroxidation. Thus, CHM is likely to be useful as a multi-targeting therapy for WD pathogenesis (Figure 6).

\section{CONCLUSION}

Despite the apparent positive results, the present evidence supports, to a limited extent because of the methodological flaws and CHM heterogeneity, that CHM paratherapy can be used for patients with WD but should not be recommended as monotherapy in WD. The possible mechanisms involved are associated with reversing the ATP7B mutants, and exerting antioxidation, anti-inflammation and anti-hepatic fibrosis effects. Further rigorous RCTs, focusing on an individual CHM formula for WD, are warranted.

\section{REFERENCES}

Aggarwal, A., Aggarwal, N., Nagral, A., Jankharia, G., and Bhatt, M. (2009). A novel Global Assessment Scale for Wilson's Disease (GAS for WD). Mov. Disord. 24, 509-518. doi: 10.1002/mds.22231

Brewer, G. J. (2009). Zinc and tetrathiomolybdate for the treatment of Wilson's disease and the potential efficacy of anticopper therapy in a wide variety of diseases. Metallomics 1, 199-206. doi: 10.1039/b901614g

Brewer, G. J., Askari, F., Dick, R. B., Sitterly, J., Fink, J. K., Carlson,. M., et al. (2009). Treatment of Wilson's disease with tetrathiomolybdate: V. Control of free copper by tetrathiomolybdate and a comparison with trientine. Transl. Res. 154, 70-77. doi: 10.1016/j.trsl.2009.05.002

Bull, P. C., Thomas, G. R., Rommens, J. M., Forbes, J. R., and Cox, D. W. (1993). The Wilson disease gene is a putative copper transporting Ptype ATPase similar to the Menkes gene. Nat. Genet. 5, 327-337. doi: 10.1038/ng1293-327

Chen, H. J., Liang, T. M., Lee, I. J., Huang, Y. T., and Lin, Y. L. (2013). Scutellariae radix suppresses LPS-induced liver endothelial cell activation and inhibits hepatic stellate cell migration. J. Ethnopharmacol. 150, 835-842. doi: 10.1016/j.jep.2013.08.049

Chen, J. L., and Wang, D. H. (2008). Observation of liver function and cirrhosis on patients with Wilson's disease treated by Shuganlidanpaidu Decoction (Chinese). J. N. Chin. Med. 38, 28-29. doi: 10.13457/j.cnki.jncm.2008.12.026

Chen, J. L., and Wang, D. H. (2010). Clinical observation on 59 cases of Wilson's disease treated by chaihuang gandou pulvis (Chinese). Sichuan Trad. Chin. Med. 1, 72-74.

Cheng, C. W., Wu, T. X., Shang, H. C., Li, Y. P., Altman, D. G., Moher,. D., et al. (2017). CONSORT extension for chinese herbal medicine Formulas2017:recommendations, explanation, and elaboration (Traditional Chinese Version). Ann. Intern. Med. 167, W7-W20. doi: 10.7326/IsTranslatedFrom_M17-2977_1

Chinese Medical Association of Neurology (2008). Guidelines for the diagnosis and treatment of hepatolenticular degeneration (Chinese). Chin. J. Neurol. 8, 566-569. doi: 10.3321/j.issn:1006-7876.2008.08.022

Choi, R. J., Ngoc, T. M., Bae, K., Cho, H. J., Kim, D. D., Chun, J., et al. (2013). Anti-inflammatory properties of anthraquinones and their relationship with the regulation of P-glycoprotein function and expression. Eur. J. Pharm. Sci. 48, 272-281. doi: 10.1016/j.ejps.2012.10.027

Coffey, A. J., Durkie, M., Hague, S., McLay, K., Emmerson, J., and Lo, C. (2013). A genetic study of Wilson's disease in the United Kingdom. Brain 136:1476-1487. doi: 10.1093/brain/awt035

Cui, G. X., and Zhao, Q. W. (2001). Clinical observation on 33 cases of patients with Wilson's disease treated by traditional Chinese and western medicine (Chinese). Shandong, J. Trad. Chin. Med. 20, 353-355. doi: 10.16295/j.cnki.0257-358x.2001.05.023

European Association for Study of Liver (2012). EASL clinical practice guidelines: Wilson's disease. J. Hepatol. 56, 671-685. doi: 10.1016/j.jhep.2011.11.007

\section{AUTHOR CONTRIBUTIONS}

G-QZ contribute as the senior authors and the principal investigator (PI) of this study. M-BX, P-QR, and T-YJ wrote the first draft of the manuscript and contributed to the overall design. G-QZ refined the study. P-PZ and H-YL identified reviewed studies for eligibility and performed the meta-analysis of data. All authors read, critically reviewed and approved the final manuscript.

\section{FUNDING}

This project was supported by the Young and Middle-Aged University Discipline Leaders of Zhejiang Province, China (2013277); Zhejiang Provincial Program for the Cultivation of High-level Health talents (2015).

Fang, S. Z. (2015). Effect of Gandouling Tablet on Index of Cardiac Function in Patients With Wilson's Disease and Cardiac Ultrastructure of CopperLoaded Rats (Chinese). Hefei: Master's thesis, Anhui university of Chinese medicine.

Filippi, C., and Dhawan, A. (2014). Current status of human hepatocyte transplantation and its potential for Wilson's disease. Ann. N. Y. Acad. Sci.1315,50-55. doi: 10.1111/nyas.12386

Flower, A., Witt,. C., Liu, J. P., Ulrich-Merzenich, G., Yu, H., and Lewith, G. (2011). Guidelines for randomised controlled trials investigating Chinese herbal medicine. J. Ethnopharmacol. 140,550-554. doi: 10.1016/j.jep.2011.12.017

Gomes, A., and Dedoussis, G. V. (2015). Geographic distribution of ATP7B mutations in Wilson disease. Ann. Hum. Biol. 43, 1-8. doi: $10.3109 / 03014460.2015 .1051492$

Han, H., Fang, X., Wu, L. M., Zhang, J., Fang, S. Z., He, W. S., et al. (2014). Observation of 21 cases of cognitive impairment of Wilson's disease treated by huatanquyu method (Chinese). J. Anhui Univ. Trad. Chin. Med. 33, 21-23. doi: 10.3969/j.issn.2095-7246.2014.01.009

Han, Y. Z., He, G. Y., Wang, X., Le, K., Wang, G. Q., and Yang, R. M. (1999). Comparison of therapeutic effects of gandouling tablet I and dimercaptosuccinate acid on hepatolenticular degeneration (Chinese). Chin. J. Integr. Trad. West. Med. 19, 69-70.

Hedera, P. (2017). Update on the clinical management of Wilson's disease. Appl. Clin. Genet. 10, 9-19. doi: 10.2147/TACG.S79121

Higgins, J., Altman, D., and Sterne, J. (eds.). (2011). "Chapter 8: Assessing risk of bias in included studies," in Cochrane Handbook for Systematic Reviews of Interventions. Version 5.1.0. (London: The Cochrane Collaboration). Available online at: http://handbook-5-1.cochrane.org/

Hong, M. F., Wang, G. Q., Yang, R. M., Hu, J. Y., Wang, X. P., and Lv, D. P. (2000). Effect of integrated traditional Chinese and western medicine on liver cirrhosis and liver function in patients with hepatolenticular degeneration (Chinese). Chin. J. Integr. Trad. West. Med. 20, 890-892. doi: $10.3321 /$ j.issn: $1003-5370.2000 .12 .003$

Hu, W. B., Han, Y. Z., Xue, B. C., Cheng, N., Sun, D. Y., Ye, D. Q., et al. (2011). Epidemiological investigation of Wilson disease in Hanshan county, Anhui Province. Chin. Med. J. 91, 894-897.doi: 10.3760/cma.j.issn.0376-2491.2011.13.008

Hu, Y. X. (2014). Effect of Doudou Decoction on Pulmonary Ventilation Function and Immunologic Index in Patients With Wilson's Disease and Pneumonic Ultrastructure of Model Rats (Chinese). Hefei: Master's thesis, Anhui university of Chinese medicine.

Hwang, J. K., Noh, E. M., Moon, S. J., Kim, J. M., Kwon, K. B., Park, B. H., et al. (2013). Emodin suppresses inflammatory responses and joint destruction in collagen-induced arthritic mice. Rheumatology 52, 1583-1591. doi: 10.1093/rheumatology/ket178

Ibrahim, N. A., El-Seedi, H. R., and Mohammed, M. M. (2007). Phytochemical investigation and hepatoprotective activity of Cupressus 
sempervirens L.leaves growing in Egypt. Nat. Prod. Res. 21, 857-866. doi: 10.1080/14786410601132477

Jeon, H., Cha, D. S., Ko, S. H., Park, H. J., Lee, Y. J., Lim, J. P., et al. (2008). Radical scavenging effects and protective effect of Spatholobus suberectus against $\mathrm{CCl} 4$ induced liver damage in rats. Nat. Prod. Sci. 14, 127-130. Available online at: http://www.koreascience.or.kr/article/JAKO200824067121771.page

Jiang, H. L. (2016). Effect of Gandouling Tablet on Indexes of Cerebral Hemodynamics and Vascular Injury Factor in Patients With Wilson's Disease and the Mechanism of Vascular Injury in TX Mice (Chinese). Hefei: Master's thesis, Anhui University of Chinese Medicine.

Jin, H., Lian, N., Zhang, F., Chen, L., Chen, Q., Lu, C., et al. (2016). Activation of PPAR $\gamma / \mathrm{P} 53$ signaling is required for curcumin to induce hepatic stellate cell senescence. Cell. Death. Dis. 7:e2189. doi: 10.1038/cddis.2016.92

Jin, H., Sakaida, I., Tsuchiya, M., and Okita, K. (2005). Herbal medicine Rhei rhizome prevents liver fibrosis in rat liver cirrhosis induced by a choline-deficient L-amino acid-defined diet. Life Sci. 76, 2805-2816. doi: 10.1016/j.lfs.2004.09.041

Lee, G. H., Lee, H. Y., Choi, M. K., Chung, H. W., Kim, S. W., and Chae, H. J. (2017). Protective effect of Curcuma longa L. extract on CCl(4)-induced acute hepatic stress. BMC Res. Notes 10:77. doi: 10.1186/s13104-017-2409-Z

Lee, H., Kim, Y. O., Kim, H., Kim, S. Y., Noh, H. S., Kang, S. S., et al. (2003). Flavonoid wogonin from medicinal herb is neuroprotective by inhibiting inflammatory activation of microglia. FASEB J. 17, 1943-1944. doi: 10.1096/fj.03-0057fje

Lee, H. Y., Kim, S. W., Lee, G. H., Choi, M. K., Jung, H. W., Kim, Y. J., et al. (2016). Turmeric extract and its active compound, curcumin, protect against chronic CCl4-induced liver damage by enhancing antioxidation. BMC Complement. Altern. Med. 16:316. doi: 10.1186/s12906-016-1307-6

Leinweber, B., Möller, J. C., Scherag, A., Reuner, U., Günther, P., Lang, C. J., et al. (2008). Evaluation of the Unified Wilson's Disease Rating Scale (UWDRS) in German patients with treated Wilson's disease. Mov. Disord. 23, 54-62. doi: $10.1002 / \mathrm{mds} .21761$

Li, W. J., Chen, C., You, Z. F., Yang, R. M., and Wang, X. P. (2016). Current drug managements of Wilson's disease: from west to east.Curr. Neuropharmacol.14, 322-325 doi: 10.2174/1570159X14666151130222427

Lin, Y. J., Ho, T. J., Lin, T. H., Hsu, W. Y., Huang, S. M., Liao, C. C., et al. (2015). P-coumaric acid regulates exon 12 splicing of the ATP7B gene by modulating hnRNP A1 protein expressions. Biomed 5:10. doi: 10.7603/s40681-015-0010-0

Liu, Z., Dou, W., Zheng, Y., Wen, Q., Qin, M., Wang, X., et al. (2016). Curcumin upregulates Nrf2 nuclear translocation and protects rat hepatic stellate cells against oxidative stress. Mol. Med. Rep. 13, 1717-1724. doi: $10.3892 / \mathrm{mmr} .2015 .4690$

Lutsenko, S., Barnes, N., Bartee, M., and Dmitriev, O.Y. (2007). Function and regulation of human copper-transporting ATPases. Physiol. Rev. 87, 1011-1046. doi: 10.1152/physrev.00004.2006

Mishra, S. K., Tiwari, S., Shrivastava, A., Srivastava, S., Boudh, G. K., Chourasia, S. K., et al. (2014). Antidyslipidemic effect and antioxidant activity of anthraquinone derivatives from Rheum emodi rhizomes in dyslipidemic rats. J. Nat. Med. 68, 363-371. doi: 10.1007/s11418-013-0810-z

Moher, D., Liberati, A., Tetzlaff, J., Altman, D. G., and The PRISMA Group. (2009). Preferred reporting items for systematic reviews and meta-analyses: the PRISMA statement. PLoS Med. 6: e1000097. doi: 10.1371/journal.pmed. 1000097

Mustafa, H. (2016). The role of curcumin in streptozotocin-induced hepatic damage and the trans-differentiation of hepatic stellate cells. Tissue Cell 48, 81-88. doi: 10.1016/j.tice.2016.02.003

Nicholl, D., Flint, S., Olsson, L., Plitz, T., Bjartmar, C., and Schilsky, M. L. (2017). Bis-choline tetrathiomolybdate in patients with Wilson's disease: an openlabel, multicentre, phase 2 study. Lancet Gastroenterol. Hepatol. 2, 869-876. doi: 10.1016/S2468-1253(17)30293-5

Pan, T. L., Wang, P. W., Huang, C. H., Leu, Y. L., Wu, T. H., Wu, Y. R., et al. (2015). Herbal formula,Scutellariae radix and Rhei rhizoma attenuate dimethylnitrosamine-induced liver fibrosis in a rat model. Sci. Rep. 5:11734. doi: 10.1038/srep11734

Panossian, A., Davtyan, T., Gukassyan, N., Gukasova, G., Mamikonyan, G., Gabrielian, E., et al. (2002). Effect of andrographolide and Kan JangFixed combination of extract SHA-10 and extract SHE-3-On proliferation of human lymphocytes, production of cytokines and immune activation markers in the whole blood cells culture. Phytomedicine 9, 598-605 doi: 10.1078/094471102321616409

Park, E. J., Zhao, Y. Z., Lian, L., Kim, Y. C., and Sohn, D. H. (2005). Skullcapflavone I from Scutellaria baicalensis induces apoptosis in activated rat hepatic stellate cells. Planta Med. 71, 885-887. doi: 10.1055/s-2005-871280

Patil, M., Sheth, K. A., Krishnamurthy, A. C., and Devarbhavi, H. (2013). A review and current perspective on Wilson disease. J. Clin. Exp. Hepatol. 3, 321-336. doi: 10.1016/j.jceh.2013.06.002

Paulino, N., Paulino, A. S., Diniz, S. N., de Mendonça, S., Gonçalves, I. D., Faião Flores, F., et al. (2016). Evaluation of the anti-inflammatory action of curcumin analog (DM1): Effect on iNOS and COX-2 gene expression and autophagy pathways. Bioorg. Med. Chem. 24, 1927-1935. doi: 10.1016/j.bmc.2016.03.024

Petrukhin, K., Fischer, S. G., Pirastu, M., Tanzi, R. E., Chernov, I., Devoto, M., et al. (1993). Mapping,cloning and genetic characterization of the region containing the Wilson disease gene. Nat. Genet. 5, 338-343. doi: 10.1038/ng1293-338

Ren, M. S., Zhang, B., Yang, R. M., Han, Y. Z., and Wang, X. (1997). Clinical study on treatment of hepatolenticular degeneration with integrated traditional Chinese and western Medicine (Chinese). Chin. J. Integr. Trad. West. Med. $6,136-138$

Roberts, E. A., and Schilsky, M. L., American Association for Study of Liver Diseases. (2008). Diagnosis and treatment of Wilson disease: an update. Hepatology 47, 2089-2111. doi: 10.1002/hep.22261

Rosencrantz, R., and Schilsky, M. (2011). Wilson disease: pathogenesis and clinical considerations in diagnosis and treatment. Semin. Liver Dis. 31, 245-259. doi: 10.1055/s-0031-1286056

Samarghandian, S., Azimi-Nezhad, M., Farkhondeh, T., and Samini, F. (2017). Anti-oxidative effects of curcumin on immobilization-induced oxidative stress in rat brain, liver and kidney. Biomed. Pharmacother. 87, 223-229. doi: 10.1016/j.biopha.2016.12.105

Schulz, K., Altman, D., Moher, D., and CONSORT Group. (2010). Consort 2010 statement: updated guidelines for reporting parallel group randomised trials. PLoS Med. 7:e1000251. doi: 10.1371/journal.pmed.1000251

Shia, C. S., Juang, S. H., Tsai, S. Y., Chang, P. H., Kuo, S. C., Hou, Y. C., et al. (2009). Metabolism and pharmacokinetics of anthraquinones in Rheum palmatum in rats and ex vivo antioxidant activity. Planta Med. 75, 1386-1392. doi: 10.1055/s-0029-1185725

Shu, M., Hu, X., Hung, Z., Huang, D., and Zhang, S. (2016). Effects of tanshinone IIA on fibrosis in a rat model of cirrhosis through heme oxygenase-1, inflammation, oxidative stress and apoptosis. Mol. Med. Rep. 13, 3036-3042. doi: $10.3892 / \mathrm{mmr} .2016 .4886$

Taichman, D. B., Sahni, P., Pinborg, A., Peiperl, L., Laine, C., James, A., et al. (2017). Data sharing statements for clinical trials. BMJ 357:j2372. doi: $10.1136 /$ bmj.j2372

Tsai, M., Lin, Y., and Huang, Y. (2011). Differential inhibitory effects of salvianolic acids on activation of rat hepatic stellate cells by platelet-derived growth factor. Planta. Med. 77, 1495-1503. doi: 10.1055/s-0030-1270783

van den Berghe, P. V., Stapelbroek, J. M., Krieger, E., de Bie, P., van de Graaf, S. F., de Groot, R. E., et al. (2000). Reduced expression of ATP7B affected by Wilson disease-causing mutations is rescued by pharmacological folding chaperones 4-phenylbutyrate and curcumin. Hepatology 50, 1783-1795. doi: 10.1002/hep.23209

Vetriselvan, S., Subasini, U., Rajamanickam, C., and Thirumurugu, S. (2011). Hepatoprotective activity of Andrographis paniculata in ethanol induced hepatotoxicity in albino wistar rats. Pharmacie Glob. 2, 1-4. Available online at: journaldatabase.info/articles/research_hepatoprotective_activity_ andrographis.html

Walshe, J. M. (2009). The conquest of Wilson's disease. Brain 132, 2289-2295. doi: 10.1093/brain/awp149

Wang, H., Yang, W. M., Bao, Y. C., Wang, M. X., Han, H., Wang, X. Y., et al. (2010). Effects of ganodu ling tablet on T cells and NK cells in 58 cases of patients with Wilson's disease (Chinese). Clin. J. Trad. Chin. Med. 22, 963-964. doi: 10.16448/j.cjtcm.2010.11.007

Wang, J., Miao, M., Zhang, Y., Liu, R., Li, X., Cui, Y., et al. (2015). Quercetin ameliorates liver injury induced with Tripterygium glycosides by reducing oxidative stress and inflammation Can. J. Physiol. Pharmacol. 93, 427-433. doi: 10.1139/cjpp-2015-0038

Wang, Y., Lou, X. T., Shi, Y. H., Tong, Q., and Zheng, G. Q. (2019).Erxian decoction, a Chinese herbalformula, for menopausal syndrome: an updated 
systematic review. J. Ethnopharmacol. 15, 8-20. doi: 10.1016/j.jep.2019. 01.010

Wang, Y., Xie, C. L., Fu, D. L., Lu, L., Lin, Y., Dong, Q. Q., et al. (2012). Clinical efficacy and safety of Chinese herbal medicine for Wilson's disease: a systematic review of 9 randomized controlled trials. Complement. Ther. Med. 20, 143-154. doi: 10.1016/j.ctim.2011.12.004

Weiss, K. H., Askari, F. K., Czlonkowska, A., Ferenci, P., Bronstein, J. M., Bega, D., et al. (2015). Prospective pilot study of a single daily dosage of trientine for the treatment of Wilson disease. Dig. Dis. Sci. 60,1433-1439. doi: 10.1007/s10620-014-3495-6

Xiao, L. M. (2003). Clinical observation on treatment of hepatic fibrosis in patients with Wilson's disease by integrated traditional Chinese and western medicine (Chinese). Hubei J. Trad. Chin. Med. 25, 9-10. doi: 10.3969/j.issn.1000-0704.2003.12.004

Xu, G. C., Chen, H. Z., Zhang, J., Fang, X., Li, J., Ge, Q., et al. (2012a). Observation on improvement of 24-hour urinary excretion of copper and improvement effect in treatment of hepatolenticular degeneration by gandou decoction (Chinese). Clin. J. Trad. Chin. Med. 24, 1055-1057. doi: $10.16448 /$ j.cjtcm.2012.11.041

Xu, G. C., Zhang, J., and Chen, H. Z. (2012b). Effect of gandouling tablet on portal hemodynamics in patients with Wilson's disease (Chinese). Clin. J. Trad. Chin. Med. 24, 204-205. doi: 10.16448/j.cjtcm.2012.03.027

Xue, B. C., Yang, R. M., Hu, J. Y., Han, Y. Z., and Wang, J. H. (2007). Study on the mechanism of liver fibrosis in patients with Wilson's disease treated by gandou decoction No.2 (Chinese). Anhui Med. J. 28, 296-299. doi: 10.3969/j.issn.1000-0399.2007.04.005

Yang, R. M. (1995). Hepatolenticular Degeneration. Hefei: Science and Technology Publishing House of Anhui.

Yue, S., Hu, B., Wang, Z., Yue, Z., Wang, F., Zhao, Y., et al. (2014). Salvia miltiorrhiza compounds protect the liver from acute injury by regulation of p38 and NFKB signaling in Kupffer cells. Pharm. Biol. 52, 1-8. doi: 10.3109/13880209.2014.889720

Zhang, B. J., Xu, D., Guo, Y., Ping, J., Chen, L. B., and Wang, H. (2008). Protection by and anti-oxidant mechanism of berberine against rat liver fibrosis induced by multiple hepatotoxic factors. Clin. Exp. Pharmacol. Physiol. 35, 303-309. doi: 10.1111/j.1440-1681.2007.04819.x

Zhang, H. B. (2007). Effect of dahuang gandou decoction combined with penicillamine on Wilson's disease (Chinese). Int. J. Trad. Chin. Med. 29, 141-143.

Zhang, J., Bao, Y. C., Xie, D. J., Tong, J. B., Zhou, L., Ding, W. J., et al. (2014a). Effect of gandouling tablet on indexes of urinary microprotein in patients with Wilson's disease (Chinese). J. Anhui Univ. Trad. Chin. Med. 33, 22-25. doi: 10.3969/j.issn.2095-7246.2014.03.008

Zhang, J., Chen, H. Z., Li, L. Y., and Fang, X. (2014b). Effect of gandou decoction combined with sodium dimercaptopropanesulfonate on the indicator of portal circulation in patients with Wilson's disease(Chinese). J. N. Chin. Med. 24, 57-59. doi: 10.13457/j.cnki.jncm.2014.01.076

Zhang, S., Chen, S., Li, W., Guo, X., Zhao, P., Xu, J., et al. (2011). Rescue of ATP7B function in hepatocyte-like cells from Wilson's disease induced pluripotent stem cells using gene therapy or the chaperone drug curcumin. Hum. Mol. Genet. 20, 3176-3187. doi: 10.1093/hmg/ddr223

Zhou, X., Cheung, C. M., Yang, J. M., Or, P. M., Lee, W. Y., and Yeung, J. H. (2015). Danshen (Salvia miltiorrhiza) water extract inhibits paracetamolinduced toxicity in primary rat hepatocytes via reducing CYP2E1 activity and oxidative stress. J. Pharm. Pharmacol. 67, 980-989. doi: 10.1111/jphp. 12381

Conflict of Interest Statement: The authors declare that the research was conducted in the absence of any commercial or financial relationships that could be construed as a potential conflict of interest.

Copyright (c) $2019 \mathrm{Xu}$, Rong, Jin, Zhang, Liang and Zheng. This is an open-access article distributed under the terms of the Creative Commons Attribution License (CC $B Y)$. The use, distribution or reproduction in other forums is permitted, provided the original author(s) and the copyright owner(s) are credited and that the original publication in this journal is cited, in accordance with accepted academic practice. No use, distribution or reproduction is permitted which does not comply with these terms. 